\title{
El Mercosur en el nuevo escenario político regional: más allá de la coyuntura
}

\author{
Juliana Peixoto Batista* \\ DANIELA PERROTTA* ${ }^{* *}$
}

Artículo recibido: 29 de mayo de 2017

Artículo aprobado: 15 de agosto de 2017

Doi: http://dx.doi.org/10.12804/revistas.urosario.edu.co/desafios/a.5767

Para citar este artículo: Peixoto Batista, J., \& Perrotta, D. (2018). El Mercosur en el nuevo escenario político regional: más allá de la coyuntura. Desafíos, 30(1), 91-134. Doi: http:// dx.doi.org/10.12804/revistas.urosario.edu.co/desafios/a.5767

\section{Resumen}

En medio de los recientes cambios en los contextos politico y económico en América del Sur, este trabajo se dedica a analizar los desafios del Mercosurpara discutir la "supervivencia” del bloque regional, sus límites y posibilidades. Se sostiene que el Mercosur es un proceso complejo y muestra características hibridas desde su concepción. Por un lado, no puede ser identificado del todo con el regionalismo abierto, paradigma predominante al momento de su creación, pero por otro lado, la definición de regionalismo posthegemónico tampoco es del todo adecuada para definir los cambios ocurridos en el bloque desde 2003. En ese sentido, el bloque posee una dinámica propia — fuertemente determinada por la alianza estratégica entre Argentina y Brasily por variables estructurales como las asimetrías en el tamaño de los mercados, el desarrollo y la diversificación del tejido

* Investigadora del Área de Relaciones Internacionales de la Facultad Latinoamericana de Ciencias Sociales (Flacso), Buenos Aires, Argentina. Correo electrónico: jpeixoto@flacso. org.ar ORCID: http://orcid.org/0000-0003-0341-5909

** Investigadora asistente del Consejo Nacional de Investigaciones Científicas y Técnicas (CONICET), con sede en el Instituto de Investigación en Ciencias de la Educación (IICE), Facultad de Filosofía y Letras de la Universidad de Buenos Aires (UBA), Argentina. Correo electrónico: danielaperrotta@gmail.com ORCID: http://orcid.org/0000-0003-1060-5129 
productivo, el nivel de vulnerabilidad a shocks e interferencias externas - que se ve influenciada solo parcialmente por los ciclos politicos, diferentes y contrapuestos, vividos por el bloque desde su creación. Para observar los cambios y continuidades que dan cuenta de esa característica bibrida que posee el Mercosur y cómo se planta el bloque de cara a los recientes desafios, se analizan agendas comerciales y sociales.

Palabras clave: América Latina, Mercosur, regionalismo abierto, regionalismo posthegemónico.

\title{
Mercosur in the New Regional Context: Beyond the Juncture
}

\begin{abstract}
This article aims to analyze Mercosur as a regional integration block, its possibilities and limits. We argue that Mercosur is a complex regional block, which shows bybrid aspects since its creation. On the one hand, Mercosur cannot be classified as an openregionalism initiative, despite the fact that it emerged in the 1990s. On the other hand, the post-hegemonic regionalism definition is not accurate either to explain the changes that occurred after 2003. In fact, Mercosur has its own dynamics - built on the strategic alliance between Argentina and Brazil - which changes only partially through the influence of political cycles. With this in mind, we analyze areas such as trade, asymmetries, and education, in order to bighlight changes and continuities that constitute the bybrid character of Mercosur and have nurtured its survival during the last 27 years. Keywords: Latin America, Mercosur, open regionalism, post-hegemonic regionalism.

\section{O Mercosul no novo cenário político regional: para além da conjuntura}

\begin{abstract}
Resumo
Em meio às mudanças recentes de contexto político e económico na América do Sul, este trabalho dedica-se a analisar os desafios do Mercosulpara discutir a "supervivência" do bloque regional, os seus limites e possibilidades, nesse sentido, sustenta-se que o Mercosul
\end{abstract}


éum processo complexo e, desde a sua conceição, mostra características híbridas. Por um lado, não pode ser identificado totalmente com o regionalismo aberto, paradigma predominante ao momento da sua criação, mas por outro lado, a definição de regionalismo póshegemônico também não é completamente adequada para definir as mudanças ocorridas no bloque desde 2003. Nesse sentido, o bloque possui uma dinâmica própria, fortemente determinada pela aliança estratégica entre a Argentina e o Brasil e por variáveis estruturais como as assimetrias no tamanho dos mercados, no desenvolvimento e diversificação do tecido produtivo, o nivel de vulnerabilidade a shocks e interferências externas, que se vê influenciada só parcialmente pelos ciclos políticos, diferentes e contrapostos, vividos pelo bloque desde a sua criação. Para observar as mudanças e continuidades que dão conta dessa característica hibrida que possui o Mercosul e como se apresenta o bloque de cara aos recentes desafios, se analisam agendas comerciais e sociais.

Palavras-chave: América Latina, Mercosul, Regionalismo Aberto, Regionalismo Pós-Hegemônico.

\section{Introducción}

El escenario político y económico de América Latina ha sido trastocado en los últimos cinco años, lo que ha traído desafíos para el proceso de construcción de región del Mercosur. Del auge de las mercancías que caracterizó la primera década de los años 2000 se asiste a un gran declive de precios, que incide directamente en las posibilidades de los gobiernos de financiar las políticas sociales y de desarrollo económico a partir de la gravitación del mercado interno. A ello se suma que, tras los comicios electorales realizados en los últimos años, se ha producido un "giro a la derecha" en algunos países que habían encaminado un "giro a la izquierda" a principios del siglo XXI.

En este contexto de cambio, el objetivo de este trabajo consiste en realizar un análisis de los desafíos del Mercosur en el nuevo contexto nacional, regional y global para discutir la "supervivencia" del bloque regional, sus límites y posibilidades. En otras palabras, los arreglos políticos fundantes del Mercosur dan cuenta de su carácter híbrido (Inchauspe \& Perrotta, 2008; Celli, Salles, Tussie \& Peixoto, 2010; Perrotta, 2010): su creación estuvo motorizada por los intereses de la industria pesada y las multilatinas gravitantes de la región (Perrotta, Fulquet \& Inchauspe, 2011), así como por un sector público interesado en el proceso (Gómez 
Mera, 2005) a causa de los vientos de cambio de los años noventa. Estas condiciones se modifican solo parcialmente con el cambio de contexto y con las convergencias políticas y económicas de sus socios, particularmente de los dos mayores: Argentina y Brasil. A partir de lo anterior se entiende cómo el Mercosur — a pesar de haber nacido en el auge del regionalismo neoliberal (nuevo regionalismo o regionalismo abierto)desarrolló mecanismos para proteger la producción industrial respecto de la extrazona y encaminó varias agendas sociales para profundizar el modelo de integración, como las políticas regionales en educación, salud y sociolaborales (Inchauspe \& Perrotta, 2008; Perrotta \& Vázquez, 2010). Esta versatilidad del Mercosur permitió — con el cambio del contexto político en la región, sumado a tendencias macroeconómicas favorables - el relanzamiento del bloque en el calor del llamado regionalismo posthegemónico (Riggirrozzi \& Tussie, 2012) o regionalismo postliberal (Veiga \& Ríos, 2007; Sanahuja, 2012) que promovió algunos cambios y mantuvo estructuras previas. Así, a partir del año 2003, se efectuó el relanzamiento del proceso de integración - luego de un intento fallido de relanzamiento en el 2000 - hacia metas vinculadas con la inclusión, el desarrollo productivo y la participación social y ciudadana. El nuevo proyecto político regional desarrolló políticas públicas que fueron comprendidas en términos de regionalismo inclusivo (Vázquez, 2011), regionalismo productivo (Briceño Ruiz, 2011) y regionalismo postliberal (Sanahuja, 2012). En estos años, las reglas de juego de la integración solo fueron modificadas superficialmente, lo que derivó en un proceso de integración regional con agendas paralelas con poca articulación entre sí.

En este trabajo, sostenemos que para comprender el Mercosur como todo acuerdo de integración- es preciso adoptar una postura que dé cuenta de la historicidad, contingencia y complejidad del proceso de construcción de región, al mismo tiempo que se han de considerar las limitaciones estructurales. En pos de este objetivo, el trabajo se organiza en cuatro secciones. En la primera se hace una introducción de las características generales del Mercosur y su carácter de proceso de integración híbrido. Las tres secciones siguientes abordan tres agendas gravitantes del proyecto de construcción de región, para analizar sus cambios y continuidades a lo largo del tiempo: la agenda comercial, tanto a nivel interno de flujos de comercio, como 
a nivel externo, en términos de las negociaciones de acuerdos marco y de tratados comerciales con terceros países o grupos de países; la agenda de asimetrías, es decir, cómo el bloque incluye el tema de reducción de asimetrías, en tanto cuestión estructural, en las dimensiones comerciales internas y externas y sus variaciones a lo largo del tiempo; la construcción del regionalismo social del Mercosur a partir de la gravitación que tuvieron agendas como la educativa, la de desarrollo social, la de agricultura familiar y del sector cooperativo, entre otras, prestando especial atención a la primera de estas con el fin de identificar cómo se expresa la hibridez y los desafíos del momento actual. Al final, se esbozan algunas consideraciones.

La elección de las agendas se justifica alrededor del argumento principal. En primer lugar, los flujos comerciales intrarregionales dan cuenta de la dinámica propia del bloque y la composición del flujo: su carácter estructural. El estudio de las negociaciones externas permite observar la postura del bloque con relación al mundo, sin que eso se refleje en cambios más profundos. Las asimetrías muestran, en su faceta interna, los cambios ocurridos en cuanto al trato de las desigualdades y en su faceta externa, que dichas alteraciones no fueron suficientes para cambiar la postura del bloque en las negociaciones. $\mathrm{El}$ análisis de las agendas sociales da cuenta de que los cambios en etapas políticamente contrapuestas fueron apenas parciales; en especial la agenda educativa permite abordar la hibridez del Mercosur toda vez que se trata de un área que ha tenido desarrollos en las tres etapas que señalamos, que trascienden el momento del apogeo de las agendas no-comerciales o agendas sociales del Mercosur y ha sido incorporada apenas iniciado el proceso de construcción de región.

\section{El Mercosur, un híbrido sobreviviente}

En los desarrollos teóricos sobre las oleadas de integración regional en América Latina (Dabène, 2009, 2012; Sanahuja, 2012; Puntigliano \& Briceño Ruiz, 2013) se ha analizado en los últimos años la emergencia de una tercera oleada de regionalismo, denominado regionalismo postliberal (Motta Veiga \& Rios, 2007; Sanahuja, 2008), posthegemónico 
(Riggirozzi \& Tussie, 2012), del eje revisionista (Briceño Ruiz, 2006) o nuevo regionalismo estratégico (Aponte García, 2014). Dicha definición se constituye en contraposición a la segunda oleada, característica de los años noventa, de inclinación neoliberal que a su vez había representado un giro con relación a la primera oleada característica de los años cincuenta del siglo Xx denominado regionalismo cerrado o recientemente titulado regionalismo autonómico (Briceño Ruiz, 2006).

Así, de manera estilizada, se puede afirmar que la primera ola de regionalismo en la región, en el marco del estructuralismo cepalino, buscaba promover la integración regional para lograr economías de escala y corregir las deficiencias del modelo de industrialización por sustitución de importaciones (ISI), con una enérgica intervención del Estado en la economía con foco en la política industrial, importante presencia de empresas públicas en los sectores estratégicos de la economía y una fuerte regulación de la inversión extranjera directa (IED). Ello de la mano del objetivo de superar la situación de dependencia y lograr ciertos niveles de autonomía promoviendo mejores condiciones de vida a la población. De hecho, muchos de los índices socioeconómicos de la región presentaron muy buenos desempeños en ese periodo (Ocampo, 2011). El modelo cepalino se gestó a partir de tres supuestos teóricos que no lograron consolidarse en medio de dictaduras militares, lo que derivó en los problemas que tuvo esta forma de integración: planificación económica e industrialización para la realización de inversiones en sectores estratégicos, con un criterio de distribución de las mismas, que permitiera la reducción de las asimetrías preexistentes entre los países; la presencia de burguesías nacionales con conciencia industrialista e integracionista y con poder político, y gobiernos de tipo desarrollista con un sector público pujante de empresas nacionales, amplio apoyo popular y circunstancias internacionales favorables (Teubal, 1968). Como ejemplos de estas iniciativas podemos citar el Mercado Común Centro Americano (MCCA), la Asociación Latinoamericana de Libre Comercio (ALALC) y el Pacto Andino ${ }^{1}$. En ese momento la clave era la política industrial.

\footnotetext{
1 La propia creación del Pacto Andino refleja el fracaso de la ALALC de dar respuestas a las asimetrías entre el eje ABRAMEX y los países andinos.
} 
La segunda oleada, también conocida como regionalismo abierto, estuvo marcada por concebir el regionalismo o la integración regional (Perrotta, 2013) como una herramienta para la mejor inserción internacional de las economías de la región. El auge del paradigma neoliberal, en un contexto de debilidad de los países de América Latina ante la crisis de la deuda, fue el escenario para el lanzamiento y relanzamiento de acuerdos comerciales regionales que ayudaron a consolidar las reformas estructurales en los diferentes países de la región. En ese nuevo panorama, ni la cercanía ni el nivel de desarrollo fueron impedimentos para los acuerdos omc Plus, así llamados porque profundizaban reglas establecidas por la recién creada Organización Mundial del Comercio (OMC). Acuerdos asimétricos como el Tratado de Libre Comercio de América del Norte (TLCAN) fueron establecidos, así como el lanzamiento de negociaciones hemisféricas como el Acuerdo de Libre Comercio de las Américas (ALCA). En dicho momento la clave eran los tratados de libre comercio.

Luego de más de una década de regionalismo abierto, la llegada de la llamada "nueva izquierda" vino a jugar un papel decisivo en la revisión de los procesos de integración en América Latina, de la mano de los altos niveles de descontento con las reformas neoliberales de la década anterior que fallaron en generar el crecimiento prometido, incluir políticamente los amplios grupos excluidos y promover modelos más equitativos de distribución (Tussie \& Heidrich, 2008; Sader, 2009; Vilas, 2011). Esa percepción de haber pagado un precio muy alto por resultados modestos impactó directamente los procesos de integración (Celli, Salles, Tussie \& Peixoto, 2010). Ese nuevo momento de la integración se ha denominado en la literatura como la tercera oleada de regionalismo (Dabène, 2012): regionalismo postliberal (Motta Veiga \& Rios, 2007; Sanahuja, 2008) o posthegemónico (Riggirozzi \& Tussie, 2012) para citar algunos de los términos más utilizados. Entre las características atribuidas a esta ola se destacan el retorno a la política y al rol conductor del Estado de la agenda de desarrollo, la búsqueda de mayor autonomía frente al mercado, el fomento a la cooperación sur-sur en agendas no comerciales, la atención a temas sociales y de asimetrías; así como a temas de infraestructura e integración productiva, entre otros (Sanahuja, 2012). Como ejemplos de la tercera oleada se apunta 
la Unión de Naciones Suramericanas (UNASUR), aunque también se extiende el concepto a la Alianza Bolivariana de los Pueblos de Nuestra América - Tratado de los Pueblos (ALBA-TCP). De todos modos, aunque el concepto no se aplique al Mercosur como tal, el cambio de orientación del regionalismo en la región se ha iniciado en su núcleo, en la alianza entre Lula y Kirchner (consolidada con el Consenso de Buenos Aires) y con el acercamiento a Chávez, y ha tenido efecto en la agenda del bloque que fue relanzado en 2003. Vale mencionar que la convergencia macroeconómica entre los dos socios más grandes del bloque contribuyó para el éxito del relanzamiento, que consistió entre otras cosas en la profundización del Mercosur político y social, la reconfiguración de temas comerciales desde la perspectiva estructural como la promoción de la integración productiva (Inchauspe, 2011; Botto, 2015; Trucco, 2017) y la reducción de asimetrías como se verá más adelante.

Desde mediados de 2012, el impulso de esa nueva etapa ha perdido fuerza a causa de la suspensión política de Paraguay y la compleja incorporación de Venezuela como Estado parte, panorama que se ha agravado al calor de las crisis en Brasil y Venezuela, el resultado de las elecciones de 2015 en Argentina, el fracaso del referéndum constitucional en Bolivia y las tensiones crecientes en Ecuador, por citar cinco grandes pilares de la UNASUR y del ALBA-TCP. De hecho, Venezuela fue suspendida por el bloque a mediados del 2017.

El Mercosur, en esa caracterización, suele ser relacionado con el regionalismo abierto, mayormente teniendo en cuenta el momento de su creación: el auge de la segunda oleada, de la mano de la motorización de las industrias petroquímicas y siderúrgicas (Sánchez Bajo, 1999), con una agenda OMC Plus. Sin embargo, ello no es del todo atinado. El bloque fue creado el 26 de marzo de 1991 por medio del Tratado de Asunción (TA) entre Argentina, Brasil, Paraguay y Uruguay, que se construyó a partir del proceso de integración argentino-brasileño iniciado a mediados de la década de los años 80: la puesta en marcha de protocolos sectoriales de cooperación basados en la búsqueda de complementariedades y de carácter flexible. Es decir, el TA recupera un conjunto de ideas para alcanzar una integración profunda - a 
partir de la creación de un mercado común y la batería de políticas vinculadas a su puesta en marcha_ aunque también forma parte del contexto político-económico e ideológico de principios de los años noventa que prescribe un tipo de construcción de región peculiar: el regionalismo abierto. Con la firma del Protocolo de Ouro Preto (POP) en 1994, los países del Mercosur limitaron el esquema de integración económica a una unión aduanera, pero el establecimiento del arancel externo común (AEC) para el comercio de bienes de tipo escalonado da cuenta de los elevados niveles de protección industrial. En efecto, el AEC adoptado reflejó la estructura tarifaria de Brasil y el ejercicio de lobby de las empresas multinacionales y/o translatinas sobre los respectivos gobiernos para beneficiarse del acceso al mercado ampliado y, en algunos casos, proteger su sector cuando no se contaba con la competitividad natural para hacerlo (Sánchez Bajo, 1999; Tussie, Botto \& Delich, 2004; Botto \& Quiliconi, 2007). El POP también estableció la estructura jurídica e institucional definitiva del Mercosur, a la que se adicionaran otros protocolos posteriores para modificar el sistema de solución de disputas (Protocolo de Olivos) o bien para crear institucionalidad adicional (Protocolo Constitutivo del Parlamento del Mercosur).

Así, el Mercosur es un híbrido y esa característica estructural suya se agudiza en el tiempo porque los procesos de integración no se agotan con su ciclo político sino que se van acumulando a través de los tiempos en varias “camadas de integración”. En este sentido, los más de 25 años de desarrollo del Mercosur pueden ser abordados a partir de tres etapas, dando cuenta de la flexibilidad y el pragmatismo del acuerdo para acomodar las políticas regionales a las orientaciones generales de los diferentes "ciclos" políticos. En primer lugar, la etapa del regionalismo abierto, desde su creación hasta la triple crisis política, económica y social de Argentina, que permeó en los demás socios, de fines del 2001. En segundo lugar, la etapa del regionalismo de la tercera oleada, que vamos a denominar redistributivo —en la literatura, regionalismo posthegemónico, postliberal, estratégico o postcomercial— que se desarrolla desde el Consenso de Buenos Aires 
en 2003 hasta la cumbre presidencial de junio de 2012². En tercer lugar, la etapa actual, a partir del cambio de orientación política en Argentina y Brasil, la pronunciada caída de los precios de materias primas - en un escenario muy complejo marcado por la crisis e inestabilidad en Venezuela- y la crisis político-institucional de los dos mayores socios del bloque.

En los apartados siguientes se abordarán algunos de los aspectos del Mercosur que dan cuenta de los cambios y continuidades en las agendas del bloque en esas diferentes etapas, que demuestran la hibridez que le es característica y que permiten hoy por hoy argumentar su supervivencia.

\section{El comercio intrazona y las negociaciones comerciales externas}

El Mercosur surge en 1991, en la era de los regionalismos abiertos, con una orientación OMC Plus pero inspirándose en modelos más profundos de integración, dado que aspiraba a ser un mercado común a la europea. Es decir, en primer lugar, el Mercosur nace aspirando a un modelo de integración a la vieja usanza en una época donde ya la gran mayoría de los acuerdos adoptaban el modelo de zonas de libre comercio o tratados bilaterales de comercio. Ese objetivo fue limitado a una unión aduanera en 1994 con el POP y si bien se puede decir que es una zona de libre comercio exitosa — casi el $90 \%$ de las posiciones arancelarias está en condición de libre comercio según el SELA (2015)— la unión aduanera presentó varios desafíos antes de su consolidación.

En ese contexto, si bien el comercio intrarregional logró la condición de zona de libre comercio en los primeros años de consolidación del bloque, alcanzando picos que sobrepasaron el $25 \%$ en el total del comercio del bloque, desde el año 2001 su porcentaje oscila en un porcentaje mucho

\footnotetext{
2 Ese momento coincide con el golpe de Estado al gobierno de Lugo (Paraguay) y la aplicación de la cláusula democrática comprendida en el Protocolo de Ushuaia — suspensión de los derechos de participación política de Paraguay-y la incorporación de la República Bolivariana de Venezuela como Estado parte, aun sin la aprobación del Congreso paraguayo.
} 
más modesto, como se observa en el gráfico 1. La composición del comercio intrazona también se ha mantenido estable y desde su creación se observa un fuerte predominio de autos y autopartes, además de productos de la industria petroquímica y siderúrgica (BID-INTAL, 2015).

\section{Gráfico 1. Mercosur: exportaciones intrabloque, al resto de ALC y al resto del mundo (Participación \%)}

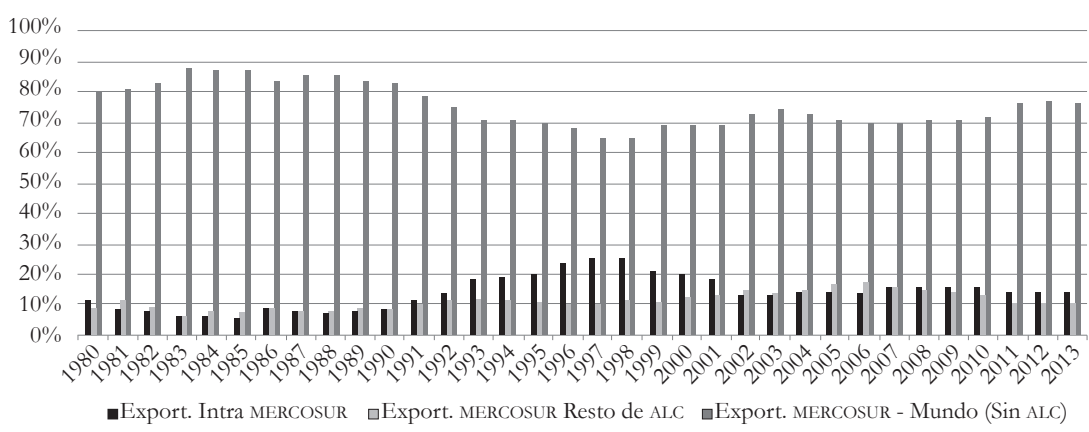

Fuente: SELA (2015).

En los años previos a la creación del bloque, el comercio entre sus países no alcanzaba el 10\%. En los primeros años de su fundación, al ritmo del Plan de Liberalización Comercial, sostuvo un crecimiento de los porcentajes entre los años 1991 y 1998, llegando a sobrepasar el 25\% en 1997 y 1998. A partir de 1999 la participación del comercio intrazona en el total del comercio ha declinado sostenidamente hasta quedar en un movimiento oscilatorio más o menos constante entre el 13 y el 16\% desde 2003.

En términos absolutos, el comercio del Mercosur ha crecido, pero mostró una leve caída en los últimos años de la década del noventa y una caída abrupta en 2008 y 2009 a raíz de la crisis global, como muestra el gráfico 2.

Durante la segunda mitad de la década del noventa, el Mercosur empezó a acumular conflictos comerciales y ante las señales de recesión en las economías de sus dos principales socios, esos problemas se hicieron más evidentes (Veiga \& Rios, 2007). Los principales sectores involucrados en diferentes conflictos a lo largo de esos años han sido el textil, el automotor, la línea blanca, el calzado y los lácteos 
Gráfico 2. Comercio total del Mercosur, 1990-2011

Miles de millones de USD\$

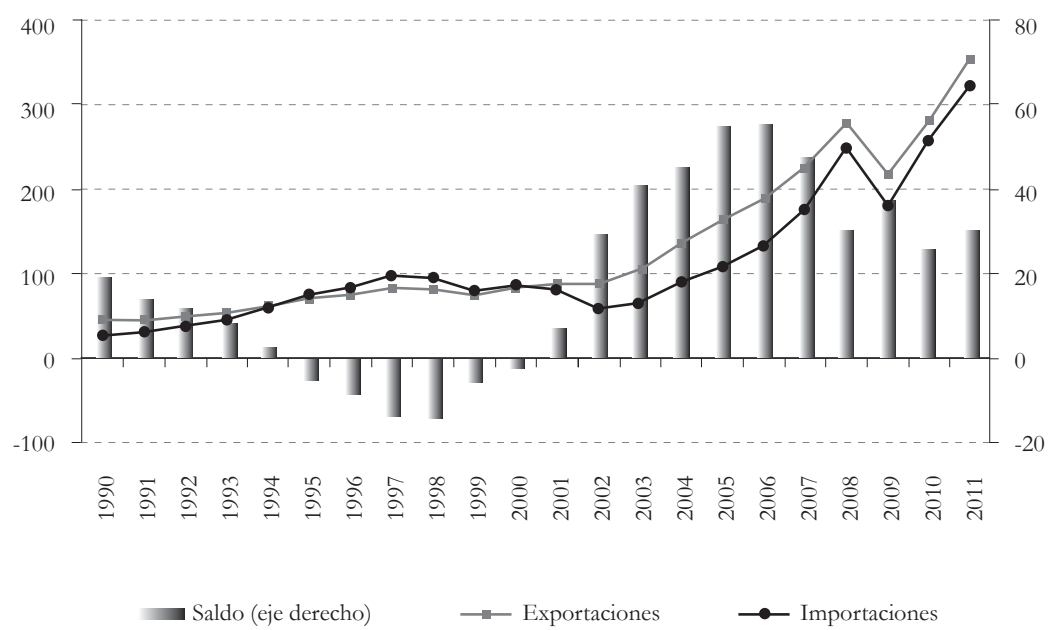

Fuente: BID-INTAL (2012).

(BID-INTAL, 2015). A ello sumado el aumento de la brecha entre las normas aprobadas y las normas implementadas, la llamada brecha de implementación que reforzaron la situación de estancamiento que duró hasta los primeros años del siglo XXI.

Con la llegada de los nuevos líderes de centro izquierda a la región, el Mercosur tomó impulso con una agenda de relanzamiento. Algunas iniciativas fueron lanzadas para promover la convergencia estructural del bloque y fomentar un aumento cualitativo en el intercambio intrarregional desde la perspectiva de la integración productiva, como se verá en el próximo apartado, pero que como se pudo observar, no han resultado en un aumento del comercio intrazona. Otro dato importante es la creciente penetración de productos de China en el mercado regional, lo que presenta desafíos crecientes para el sostenimiento de un comercio intrarregional con mayor valor agregado (Paikin \& Dulcich, 2017). 
En suma, en términos de comercio, el Mercosur no ha cambiado demasiado, salvo en tres momentos marcados: el impulso de su creación con el Plan de Liberalización Comercial, la crisis del fin del noventa y la crisis global del año 2008. Es decir, los responsables de los marcados cambios en el comercio del bloque fueron un instrumento de política comercial activa pero superficial (arancel) y dos crisis. Fuera de esas circunstancias excepcionales, los datos indican que hay un comercio intrarregional inercial en el Mercosur, un comercio que existe más allá de las convergencias y divergencias políticas y que de hecho ha atravesado dos ciclos políticos contrapuestos pero igualmente caracterizados por la escasez de políticas activas y profundas de promoción de la integración productiva que puedan romper ese techo inercial. Vale decir, luego de 26 años de existencia, dos periodos contrapuestos de confluencia política y dos severas crisis, que el Mercosur ha sobrevivido y en términos de comercio intrarregional ha permanecido, a grandes rasgos, igual ${ }^{3}$.

De todos modos, es necesario aclarar que ese es un buen desempeño en términos comparativos. De acuerdo a datos del SELA (2015), el proceso de integración con mayores tasas de crecimiento en términos de exportaciones interregionales entre 1998 y 2013 fue justamente el Mercosur, aun si se lo compara con la flamante Alianza del Pacífico (SELA, 2015), como se observa en el gráfico 3.

En términos de las negociaciones con otros bloques o países, el Mercosur muestra un comportamiento que también abona a su naturaleza híbrida. De hecho, durante el auge del regionalismo abierto, llamativamente el bloque inició escasas negociaciones, mientras que esa característica fue ganando dinamismo en plena oleada de regionalismo posthegemónico, como se puede observar en la tabla 1.

\footnotetext{
3 En ese sentido, sobre la continuidad del Mercosur en términos comerciales a pesar de los cambios políticos, ver también a Quiliconi (2013).
} 


\section{Gráfico 3. Comercio intrarregional respecto del comercio total - Mercosur x Alianza del Pacífico}

$\square 2007 \square 2008 \square 2009 \square 2011$

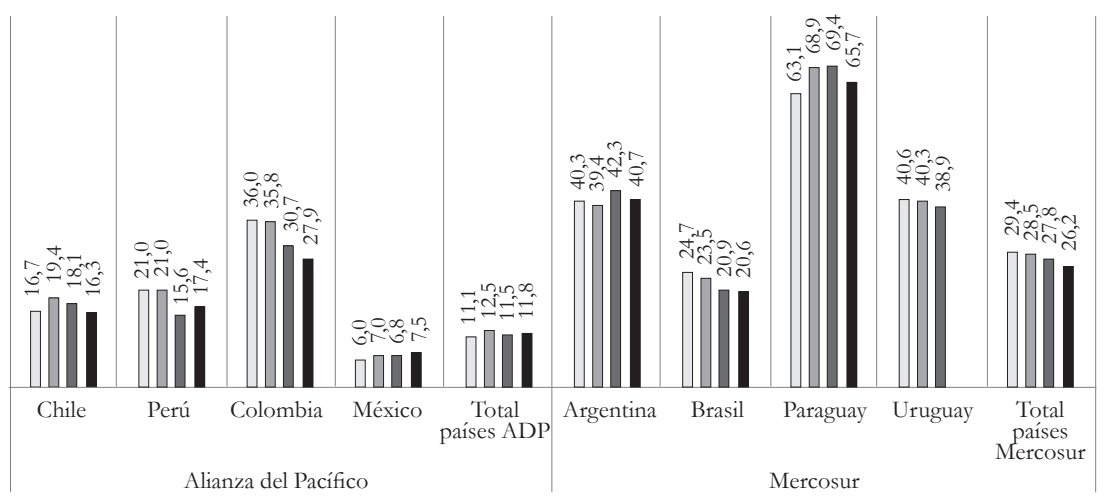

Fuente: SELA (2015).

Tabla 1. Negociaciones externas del Mercosur con países o bloques de países en las tres etapas

\begin{tabular}{|c|c|c|c|}
\hline Periodo & 1991-2002 & 2003-2012 & 2012-2016 \\
\hline $\begin{array}{l}\text { Países / } \\
\text { Bloques de } \\
\text { países }\end{array}$ & $\begin{array}{l}\text { Bolivia, Chile, UE } \\
\text { México } \\
\text { Rose Garden } \\
\text { Agreement-ALCA }\end{array}$ & $\begin{array}{l}\text { CAN (Perú, Colombia, } \\
\text { Ecuador, Venezuela) } \\
\text { India, China, SACU, consejo } \\
\text { de Cooperación del Golfo, } \\
\text { Egipto, Marruecos, Israel, } \\
\text { Cuba, Canadá, SICA, } \\
\text { CARICOM, Corea, República } \\
\text { Dominicana, Panamá, } \\
\text { Turquía, Paquistán, Jordania, } \\
\text { Siria, Haití, Autoridad } \\
\text { Palestina }\end{array}$ & $\begin{array}{l}\text { Guyana, } \\
\text { Surinam }\end{array}$ \\
\hline
\end{tabular}

Fuente: Elaboración propia con base en la información disponible en el sitio www.mercosur.int

Las primeras negociaciones del bloque fueron con Estados Unidos, con la firma del Acuerdo Jardín de Rosas (Rose Garden Agreement) en 1991, antecesor directo del ALCA, lanzado posteriormente, en 1994. Además de esa negociación temprana, las escasas negociaciones iniciadas en los noventa fueron entre Bolivia, Chile y la Unión Europea. En el caso de Bolivia, país asociado, el acuerdo fue firmado para la conformación de una ZLC y fue firmado en 1996. Fue un acuerdo sencillo de lograr teniendo en cuenta que ya había preferencias en 
la ALADI que fueron plurilateralizadas en 1995, además del hecho de que Bolivia no era un competidor para los países del bloque y era considerado un país en zona de influencia de Argentina y Brasil. En el mismo año, 1996, se firma el acuerdo con Chile para el establecimiento de una ZLC, que convirtió a Chile en el segundo país asociado del Mercosur. Con relación a Chile, el país ya había sido consultado para hacer parte del Mercosur como miembro original (ya que desde 1976 Chile no era miembro de la CAN), hecho que finalmente no sucedió entre otras cosas por la estructura productiva y arancelaria de Chile y el escaso incentivo para adoptar un AEC de las características de países más diversificados y con grandes mercados internos. En ambos casos, hubo cierto recelo por parte de Paraguay y Uruguay, que temían que se diluyeran sus preferencias de acceso a los mercados de los dos socios mayores. Situación agravada por el hecho de que los nuevos socios no estaban obligados a adoptar el AEC — como sí lo estaban Paraguay y Uruguay — ni a pagar los costos asociados a la protección de bienes industriales provenientes de Brasil y Argentina (Motta Veiga \& Rios, 2007).

Con relación a la Unión Europea, las negociaciones son parte de un acuerdo más amplio, firmado en 1995, un marco de cooperación y comercio entre ambos bloques, que incluyó tres pilares: la cooperación, el diálogo político y las negociaciones comerciales. Las negociaciones comerciales propiamente dichas empezaron en el 2000 y todavía al día de hoy no se ha llegado a un acuerdo para su firma. Vale decir que el Mercosur ha recibido muchos fondos de cooperación de parte de la UE, entre otras cosas, para la mejora institucional del bloque.

Para ese entonces, crecía el rechazo al ALCA y la llegada de la nueva izquierda a la región vino a lanzar un nuevo periodo de negociaciones externas, con mayor activismo y protagonismo. Algunos hitos son importantes en esa nueva etapa. En primer lugar, el "No al ALCA" definitivo en la Cumbre de Mar del Palta en 2005. En segundo lugar, el mayor activismo y coordinación de los cuatro países en las negociaciones de la OMC, una vez lanzada la Ronda de Doha. En tercer lugar, la mayor búsqueda de acuerdos sur-sur, como se puede observar en la tabla 1. En último lugar, el acercamiento con la CAN. 
Cabe mencionar que si bien la bibliografía identifica una línea de quiebre (un nuevo tratado de Tordesillas) para referirse a las diferentes estrategias de inserción que adoptaron los países del cono sur con costa al Atlántico y los países del cono sur con costa al Pacífico (Motta Veiga \& Rios, 2007; Valladao, 2007), ese punto merece ser matizado con relación a la relación Mercosur-CAN. Si bien la tercera oleada de regionalismo no alcanzó a los países de la costa del Pacífico de la misma manera, ya que siguieron adoptándose estrategias de inserción más relacionadas con las de los años noventa, como la firma de varios TLC con países desarrollados (EE.UU., Canadá, UE), también es cierto que los países de la CAN formaron parte de la UNASUR y hubo un relanzamiento de esta en 2003, que buscó en cierta medida realzar otras agendas de la integración, como por ejemplo la del medio ambiente, la de cohesión social, la de participación ciudadana y la del movimiento de personas. Se generó el Plan de Desarrollo Social Integrado, aprobado en 2004. En ese mismo año, se firmó un memorándum de entendimiento para encontrar bases comunes que permitieran profundizar la integración entre ambos bloques y establecer una ZLC, que son los pilares de construcción de la UNASUR según el Preámbulo del Tratado Constitutivo de esta. Esa iniciativa construída sobre el acuerdo de alcance parcial bajo el marco de ALADI a causa de la falta de consenso entre los miembros de la CAN llevó a que las negociaciones se convirtieran en bilaterales, es decir, entre el Mercosur y los miembros de la CAN (Perú, Colombia, Venezuela y Ecuador, ya que Bolivia ya había firmado el acuerdo). Posteriormente, en 2006, los desacuerdos entre el modelo de inserción llevaron a Venezuela a retirarse de la CAN (ante el inicio de las negociaciones de Perú y Colombia con EE.Uu.) e ingresar al Mercosur. El acuerdo Perú-Mercosur es del 2003, mientras que los de Ecuador, Colombia y Venezuela son del 2004. Actualmente, Venezuela es miembro pleno (a pesar de estar suspendido), mientras que Bolivia inició su proceso de adhesión en el 2007 con la culminación de su acuerdo de adhesión en el 2015, y Ecuador, que también ha solicitado su incorporación al bloque como miembro pleno, posee un grupo ad hoc desde 2011 en el Mercosur para evaluar su ingreso. 
Como se puede observar, el advenimiento del regionalismo posthegemónico significó un periodo de gran impulso negociador por parte del Mercosur, la mayoría de las negociaciones se dieron con países en desarrollo. Luego de la crisis mundial del 2008, el bloque ha reducido significativamente la apertura de nuevas negociaciones. Cabe mencionar que ese activismo no ha sido acompañado de muchos resultados concretos ya que gran parte de las negociaciones iniciadas a partir de 2004 cuentan solamente con un memorándum de entendimiento, un acuerdo marco o una reunión de acercamiento como el caso de Canadá, Corea y la Comunidad y el Mercado Común del Caribe (CARICOM). Algunas excepciones como los países de la CAN, Southern African Customs Union (SACU), India e Israel, cuyos acuerdos ya están vigentes, serán analizadas en el próximo apartado, donde se abordará cómo se ha comportado el Mercosur con relación al tema del tratamiento de asimetrías a lo largo de las dos oleadas de regionalismo.

A partir del agravamiento de las crisis en Argentina y Brasil, sumado a la crisis institucional en Paraguay en 2012, tanto la agenda de comercio interno como las negociaciones externas empezaron a perder fuerza. Actualmente, la región asiste a un regreso de gobiernos de centroderecha en Argentina y Brasil, al aumento de las tensiones en Ecuador y al estado de emergencia que vive Venezuela, lo que aumenta los cuestionamientos sobre el futuro del bloque. En ese contexto, las negociaciones externas que prácticamente se habían paralizado en los últimos años fueron retomadas con una retórica que hace recordar la década del noventa, inauguradas con un reacercamiento a Estados Unidos y la retoma de las negociaciones con la UE. En mayo de 2016, Mercosur intercambió ofertas con la UE de bienes, servicios/ inversiones y compras gubernamentales, así como de un documento que se conoce como "Condicionalidades", que refleja las posiciones de ambas partes respecto de ciertas condiciones que deben reunirse a fin de que el contenido de las ofertas que se presentan tenga efectiva validez (BID-INTAL, 2017). En cuanto al comercio interno, según datos del BID-INTAL (2017), en el periodo 2015-2016 Argentina tuvo un saldo deficitario en el comercio de bienes después de 15 años, luego de que sus exportaciones cayeran más que sus importaciones por el efecto de la crisis en Brasil. Por su parte, Brasil está inserto 
en una profunda crisis lo que hizo que las importaciones cayeran más que las exportaciones, dejando al país con superávit. Paraguay se vio afectado por el menor dinamismo de sus principales socios comerciales, en particular del Mercosur, y por la reducción de los precios de las materias primas, mientras que Uruguay tuvo una caída en importaciones a raíz de las menores compras de petróleo y de las exportaciones por la disminución de la demanda de sus principales socios comerciales.

En suma, en cuanto a la agenda comercial intrazona, es posible observar que el Mercosur como bloque nacido en medio del regionalismo abierto y a contra mano de los corolarios de ese paradigma se ha caracterizado por un comercio intrarregional basado en manufacturas de origen industrial y consecuentemente por un patrón de inserción como unión aduanera basado en una fuerte protección industrial. También se observa que ese comercio es parte del núcleo del bloque y de su dinámica propia, como se ha mencionado al inicio de este trabajo, teniendo en cuenta que se ha mantenido más o menos estable desde su creación y luego de haber atravesado dos grandes ciclos políticos contrapuestos y al menos dos crisis severas, una global y otra regional. Con relación a las negociaciones externas, si bien a primera vista se puede observar cierta confluencia entre el comportamiento del bloque y su ciclo político, ello debe matizarse por el hecho que, por un lado, en la etapa de regionalismo abierto el bloque fue muy poco activo en las negociaciones, incluida una creciente oposición al ALCA, y por el otro lado, en la etapa siguiente, de regionalismo posthegemónico, si bien el bloque hizo un viraje hacia negociaciones sur-sur, no se han logrado muchos resultados en términos de acuerdos finalizados.

\section{Un desafío subyacente: las asimetrías}

Las asimetrías entre países pueden ser clasificadas en estructurales originadas en diferencias en los tamaños de las economías, posición geográfica, dotación de factores, infraestructura, calidad institucional o nivel de desarrollo — o políticas —originadas en la ausencia o esca- 
sez de convergencia política e institucional y de coordinación entre los países- (Bouzas, 2003; Porta, 2006). En ese sentido, si bien el Mercosur presenta ambos tipos de asimetrías entre los países que lo conforman, las asimetrías estructurales son las más pronunciadas.

A pesar de ese panorama, el Mercosur nació con un enfoque muy restringido y superficial para el tratamiento de las asimetrías. Es llamativo que la palabra 'asimetría' ni siquiera esté presente en el documento fundante del bloque (Tratado de Asunción), y la única mención al respecto es el artículo 6 que establece que los miembros reconocen diferencias en los tiempos de implementación del Programa de Liberalización Económica para Paraguay y Uruguay. El enfoque restrictivo en el tratamiento de asimetrías va en la línea de lo que sucedió en el sistema multilateral de comercio en la transición del GATT hacia la OMC (Peixoto, 2010). De hecho, luego del auge a fines de los años setenta en la Ronda de Tokio, el tema sufrió una restricción significativa en su alcance, haciéndose presente en los Acuerdos de Marrakech solamente por medio de flexibilidades puntuales, plazos más laxos y otras cuestiones superficiales referidas a las asimetrías.

Cuatro años después de su formación, en 1995, el Mercosur, en el preámbulo del POP, insta a tener en consideración la situación de los países y regiones menos desarrollados. No obstante, las asimetrías del bloque siguieron siendo abordadas por medio de políticas negativas que garantizarían a los dos países más pequeños algunas flexibilidades con relación a las obligaciones asumidas (Fossati \& Levit, 2010), incluyendo listas de excepciones, reglas de origen más laxas para agregar valor a productos extrazona y regímenes de admisión temporaria (Celli, Salles, Tussie \& Peixoto, 2010). Claramente dichas medidas difícilmente tendrían impacto sobre la reducción de asimetrías y el Mercosur siguió su tendencia a la concentración económica (Calfat \& Flores Júnior, 2001). El descontento por parte de Paraguay y Uruguay con dicha situación se fue incrementando, e incluyó amenazas por parte de ambos países si se firmaba una ZLC con Estados Unidos, lo que representaría la completa dilución del AEC del bloque. 
La renovación del bloque a partir de 2003 vino a dar un nuevo aire a la agenda de tratamiento de asimetrías. A ejemplo de lo que sucedió en la Ronda de Doha, donde los países en desarrollo lucharon por la inclusión de una concepción más profunda y estructural de las asimetrías — una agenda que contó con la insistencia de Paraguay - el Mercosur empezó a ampliar su agenda de tratamiento de las asimetrías y a diseñar acciones más positivas en ese campo. El punto clave en ese sentido fue la promoción de la integración productiva, de programas como el Mercosur Pymes o el Fondo de Convergencia Estructural del Mercosur (FOCEM), quizás la iniciativa que ganó más relevancia a lo largo de los años.

A pesar de ser un programa que no posee los fondos necesarios para motorizar un cambio de mayor envergadura ${ }^{4}$, el FOCEM impulsa proyectos concretos que visan el desarrollo de la competitividad, la infraestructura y la cohesión social con relación a las economías más pequeñas y las regiones menos desarrolladas del bloque (Celli, Salles, Tussie \& Peixoto, 2010). La inclusión de las regiones menos desarrolladas atiende a otra característica peculiar del bloque, toda vez que Brasil, que es la economía más grande del bloque con el mayor PBI, posee la segunda región menos desarrollada de todo el bloque (Provincia de Maranhão), después de Paraguay.

Existen otras iniciativas, como los foros público-privados de competitividad, el Fondo de Garantía para Pymes y el Fondo de Agricultura Familiar, todos creados entre 2004 y 2009. La creación del Instituto Social del Mercosur en 2007 también se relaciona con la reducción de asimetrías, la provisión de asistencia técnica para el diseño de políticas públicas regionales, además de la búsqueda de fondos.

En esa misma dirección, el bloque aprobó, en 2008, un marco para guiar las negociaciones extraregionales. Esa medida busca resguardar los derechos de Paraguay y Uruguay frente a terceros países y tiene origen en el incremento significativo de las negociaciones por

\footnotetext{
4 El capital anual del FOCEM es de 100 millones de USD, de los cuales Brasil contribuye con el $70 \%$, Argentina con el $27 \%$, Uruguay con el 2\% y Paraguay con el 1\%.
} 
parte del bloque a partir del año 2003 que aumentaron los temores de ambos países con relación a su posición relativa en el bloque en cuanto a las preferencias y al trato más favorable. En ese sentido, al analizar algunos ejemplos de acuerdos firmados con terceros países se confirma que la precaución tiene su razón de ser.

Cabe decir que los acuerdos que involucran al Mercosur y a terceros países tienen como marco para su realización la Cláusula de Habilitación, adoptada en la Ronda de Tokio del GATT, aún vigente. Uno de sus objetivos primordiales es incrementar las relaciones comerciales entre países en desarrollo creando nuevas alternativas, reduciendo la dependencia de los mercados de los países desarrollados y promoviendo la unión entre PED para aumentar su capacidad de negociación (Celli, Salles, Tussie \& Peixoto, 2010). En ese sentido, comparada con el artículo XXIV del GATT, que regula los acuerdos comerciales regionales, posee condiciones más laxas como por ejemplo la posibilidad de acuerdos de alcance parcial —es decir, que no abarcan todo el universo de bienes intercambiados a arancel cero-.

Sin embargo, en los casos concretos, no hay a priori garantía de que una mayor interdependencia entre PED lleve a beneficios mutuos y eso es especialmente cierto en el caso de negociaciones entre grupos de PED que poseen grandes asimetrías internas, como en el caso del Mercosur, lo que puede afectar los intereses de los países o regiones de menor desarrollo relativo del bloque. En ese sentido, al analizar los acuerdos vigentes del Mercosur con países y bloques extrazona -Mercosur/Bolivia (ACE 36), Mercosur/Chile (ACE 35), Mercosur/Perú (ACE 58), Mercosur/Israel, Mercosur/saCU y Mercosur/ India-, se observan algunas peculiaridades (Celli, Salles, Tussie \& Peixoto, 2010).

Los acuerdos varían entre aquellos firmados entre el Mercosur y los países de la región —-Bolivia, Chile y Perú- y los dos acuerdos firmados con países de afuera de la región. El primer grupo de acuerdos son acuerdos de complementación económica bajo el marco de ALADI y sus textos son bastante similares, siguen un modelo estandarizado que incluye preámbulo, objetivos, programa de liberación comercial y 
demás temas como régimen de origen, prácticas desleales del comercio internacional, salvaguardias, solución de controversias, valoración aduanera, normas y reglamentos técnicos, medidas sanitarias y fitosanitarias además de anexos (cronogramas de desgravación, régimen de adecuación, régimen de origen, régimen de salvaguardias y régimen de solución de controversias). Lo llamativo de esos acuerdos es la ausencia de referencias sobre las asimetrías, salvo algunas excepciones dedicadas a flexibilidades puntuales para el caso de que existan diferencias entre los aranceles para productos exportados por Bolivia, de acuerdo al Patrimonio Histórico en el Régimen de Adecuación (artículo 4). En el caso del acuerdo con Chile, se estipulan excepciones de acceso al mercado de Chile en favor de Paraguay (artículo 50). En el caso del acuerdo con Perú, además de que es el único acuerdo que incluye el tema de propiedad intelectual, es el único que menciona la preocupación por el tema de las asimetrías (artícuilo 1), pero sin ninguna medida posterior que lo concrete.

Vale decir, salvo en los cronogramas de desgravación, donde se estipularon algunas flexibilidades y distintas velocidades, que los acuerdos del Mercosur con los tres países andinos no abordaron el tema de asimetrías de manera contundente. Cabe resaltar que si bien los acuerdos con Bolivia y Chile son de la segunda mitad de la década de los noventa, el acuerdo con Perú es del 2004, momento en que el Mercosur ya había cambiado su enfoque frente a las asimetrías.

En cuanto al otro conjunto de acuerdos, del Mercosur con países o bloques de afuera de la región, la situación es similar. El análisis de los tres acuerdos deja entrever algunas semejanzas y diferencias que merecen ser resaltadas. Tanto el acuerdo entre Mercosur y la SACU como el acuerdo con India reconocen la importancia de la promoción del comercio y la cooperación para fortalecer el comercio sur-sur. Con relación a las disciplinas comerciales propiamente dichas como medidas antidumping y compensatorias, trato nacional, valoración aduanera, berreras técnicas al comercio, medidas sanitarias y fitosanitarias, ambos acuerdos se refieren a las reglas del sistema multilateral como marco. Como regla general establecen que en los casos de temas comerciales que son también regulados por la OMC, los países 
signatarios pueden elegir entre las provisiones de solución de disputas del acuerdo o el sistema de solución de controversias de la OMC, con la excepción del caso de medidas antidumping y compensatorias del acuerdo con India, donde la OMC es el foro excluyente.

En cuanto a asimetrías, el acuerdo con India no establece ninguna flexibilidad para los países más pequeños o con menor desarrollo relativo ni en el listado de productos ni en las reglas de origen. Solo hay dos consideraciones específicas a Paraguay en productos relacionados al comino y al coco, además de una cuota adicional en el mercado de India para el aceite de soja de Paraguay. Asimismo, el mayor interés de los dos socios más pequeños del Mercosur no se refiere tanto al acceso al mercado de India sino más bien a la reducción del AEC. El acuerdo es la oportunidad para corregir parcialmente el desvío de comercio que recayó mayormente sobre ellos cuando se estableció el AEC. La disminución de los aranceles de importación de India quizás sea una ventana de oportunidad para el establecimiento de industrias de procesamiento, en un contexto de reglas de origen favorables. En todo caso, se puede afirmar que el enfoque de asimetrías utilizado en el acuerdo fue el de cuotas y aranceles.

Mientras que en el acuerdo Mercosur/India el tratamiento de las asimetrías se reduce a las listas de productos, en el acuerdo Mercosur/SACU estas son parte de sus principios fundamentales, afirmando que las negociaciones tienen en consideración los principios de trato especial y diferenciado para los países más pequeños y menos desarrollados de ambos bloques. Esto se explica por el hecho de que la SACU es un bloque heterogéneo, que incluye Botsuana, Lesoto, Namibia, Suazilandia y Sudáfrica.

Al principio del acuerdo, en el artículo 6(d), la definición de arancel aduanero excluye a los gobiernos de Botsuana, Lesoto, Namibia y Suazilandia en caso del desarrollo de industrias nacientes en virtud del acuerdo SACU. En tales situaciones se realizarán consultas en caso de que se afecten exportaciones preferenciales de Paraguay o Uruguay. Ese es el caso en que el acuerdo SACU protege a sus miembros de menor desarrollo relativo de que se diluyan sus preferencias con relación a países no miembros. Vale aclarar que esos países no tienen una obligación real de reducir aranceles si estipulan que esos aranceles son parte 
de un programa para el desarrollo de industrias nacientes, y que si llegaran a afectar exportaciones de Paraguay o Uruguay el enfoque es de caso por caso, cuyo último recurso es accionar el sistema de solución de controversias si no arriban a una solución satisfactoria. Asimismo, en el "Entendimiento entre SACU y Mercosur para la conclusión del acuerdo comercial preferencial", las partes se comprometen a expandir y profundizar el acuerdo incluyendo, entre otros sectores, la pesca, que es prioridad para los países más pequeños de ambos bloques.

Además de los dispositivos mencionados, no hay ninguna otra consideración con un trato especial y diferenciado hacia Paraguay o Uruguay, bien sea en reglas de origen, salvaguardias, procedimientos de solución de controversias o en las lista de concesiones, que consisten en 950 productos.

En suma, ninguno de los dos acuerdos es muy abarcador: cubren pocos ítems arancelarios. Además, ambos son llamativamente descuidados frente al tema de las asimetrías, sobre todo en lo que se refiere al Mercosur; se limitan a adoptar medidas aisladas para lidiar con el tema, con un enfoque muy restrictivo, que presenta algunas diferencias. El acuerdo con India protege los intereses de Paraguay en exportación de soja, mientras que el acuerdo con SACU protege los intereses de los países de menor desarrollo relativo del bloque, sin hacer ninguna mención a Paraguay o Uruguay, que solo están habilitados a iniciar consultas en los casos concretos donde sus exportaciones se puedan ver afectadas.

En contraste, el acuerdo Mercosur-Israel es más claro en el sentido de promover oportunidades para potenciar los flujos de comercio existentes y es mucho menos grandilocuente en su texto. Por ejemplo, el acuerdo no incluye preámbulo resaltando los beneficios del comercio sur-sur. Por otro lado, las reglas de origen prevén consideraciones especiales para Paraguay y Uruguay. El acuerdo también posee un anexo que prevé la cooperación para el desarrollo de sectores por medio de la transferencia de tecnología y proyectos conjuntos para desarrollar nuevas tecnologías, entre otros. Pide por especial atención no solo a las economías pequeñas del Mercosur sino también a las 
Pymes en general. En resumidas cuentas, el acuerdo Mercosur/Israel es de los seis acuerdos, el que más disposiciones relativas al manejo de asimetrías contiene. Está más orientado por oportunidades económicas concretas y menos por objetivos estratégicos.

En cuanto al manejo de asimetrías en el Mercosur, se derivan algunas reflexiones. En términos de agenda interna de reducción de las asimetrías, esta ha cambiado de una agenda superficial y restrictiva de las asimetrías a un enfoque más estructural, aunque con impactos limitados. Eso refuerza el argumento de la dinámica propia del bloque teniendo en cuenta que si bien el cambio de ciclo político permitió cambios acordes en esa agenda, no fue suficiente para traccionar cambios estructurales como aquellos relacionados con la integración productiva. En cuanto a las asimetrías en la agenda de negociaciones externas, la hibridez del Mercosur es más clara toda vez que no hay un patrón de comportamiento definido entre los ciclos políticos. En la primera y la segunda etapa de la integración se observan dos maneras de enfocar el tema. Por un lado, acuerdos con mucha retórica estratégica y pocos dispositivos concretos que resguardan los intereses de Paraguay y Uruguay como países con menor desarrollo relativo y, por otro lado, acuerdos sin retóricas pero con disposiciones escasas aunque concretas orientadas a la protección de Paraguay y Uruguay.

En el próximo apartado analizaremos algunas de las agendas sociales del Mercosur para dar cuenta de sus cambios y continuidades.

\section{Las agendas sociales de la integración}

Durante la primera década del Mercosur se desarrollaron algunas agendas de integración social, especialmente aquellas vinculadas — de manera más visible o menos controvertida - con la meta de conformar un mercado común. Por este motivo, las agendas destacadas fueron la sociolaboral y la educativa ${ }^{5}$. La primera motorizada por

\footnotetext{
Esto no quiere decir que fueron las dos únicas agendas sociales del Mercosur durante este periodo; en efecto, lo que se observa es la creación de espacios institucionales para
} 
los actores sindicales de los cuatro Estados parte desde un espacio de acción colectiva transnacional: la Coordinadora de Centrales Sindicales del Cono Sur (CCSCS). La segunda promovida por los responsables de los Ministerios de Educación con apoyo de la Organización de Estados Iberoamericanos (OEI).

La agenda sociolaboral contó con un dinamismo singular dada la movilización activa de los actores sindicales que buscaron garantizar derechos laborales en el marco regional, el que, prima facie, miraban con recelo a raíz de la experiencia internacional de sus contrapartes durante la negociación del Tratado de Libre Comercio de América del Norte (TLCAN) y las negociaciones - en curso por ese entonces- del ALCA. El accionar del actor sindical fue importante para la elaboración de un texto que recogiera niveles de protección sociolaboral en la región. No obstante, al momento de la adopción su jerarquía cambió de protocolo a declaración, lo que le restó capacidad de sanción. La agenda educativa logró encaminar acciones en tanto no se construyó en tensión con el modelo de regionalismo abierto del Mercosur —en un contexto de implementación nacional de políticas de reforma estructural también en esta área- sino que sus diferentes planes incluyeron metas que estaban acordes al proyecto regional y le permitieron ir desarrollando acciones incrementales que cimentaron la construcción posterior ante una nueva coyuntura.

Con el nuevo ciclo político-económico y la coyuntura que se abre a inicios del siglo XXI, el proceso de construcción de región del Mercosur no estuvo al margen de los procesos de cambio que se sucedieron en cada uno de los países, tanto de los Estados parte como de los asociados. Así,

abordar diferentes agendas de políticas públicas en buena parte de las áreas de gobierno de los respectivos países. Los espacios institucionales creados asumieron la forma de reuniones ministeriales, reuniones especializadas o grupos de trabajo (GT) vinculados al Grupo del Mercado Común. A título ilustrativo se pueden mencionar — para la etapa señalada— la Reunión de Ministros del Interior, la Reunión Especializada en Ciencia y Tecnología y el GT de Salud. Es posible afirmar que las agendas educativa y sociolaboral destacan en términos de la gravitación que tuvieron en esos años y que su desarrollo les permitió acumular un conjunto de capacidades de gestión y recursos que fueron capitalizados ante un nuevo contexto político regional, profundizando — especialmente en el caso de la educación— la puesta en marcha de políticas públicas regionales. 
conforme los nuevos gobiernos modificaban los mecanismos de redistribución, ensayaron instrumentos para promover la inclusión social a partir de políticas afirmativas y la promoción de un enfoque de derechos. Las nuevas orientaciones se sustentaron en un Estado revigorizado que se erigió como conductor del mercado, promotor del desarrollo y garante de derechos, así como por el fortalecimiento de los espacios de participación y movilización de actores sociales. Este proceso de la esfera nacional permeó la esfera regional y reconfiguró el statu quo dominante: de la preeminencia de la agenda comercial se pasó a la conformación de la agenda de integración y cooperación productiva, social y ciudadana. Este proceso no estuvo exento de tensiones ya que los resortes estructurales vinculados a las "reglas de juego" básicas de la integración no fueron trastocadas (Perrotta \& Porcelli, 2016). En efecto, de esto se trata la versatilidad y/o flexibilidad del Mercosur: la posibilidad de que, en un mismo arreglo regional, conforme las dinámicas nacionales y las posibilidades del contexto internacional, funcionen en paralelo proyectos políticos de región divergentes en carriles separados pero con mecanismos políticos propios de la diplomacia presidencial para dirimir las tensiones que surjan de la confrontación de visiones sobre los fines del Mercosur.

De esta manera, la puesta en marcha de las agendas de integración social fue impulsada tanto por movimientos sociales que habían iniciado lazos de cooperación previos y venían abogando por la incorporación de diferentes temáticas y perspectivas de regionalización como por actores de gobierno que en la fase anterior no habían logrado ejercer la presión política suficiente para que sus áreas de trabajo contaran con un espacio institucionalizado en el organigrama regional. Así, la nueva receptividad a estas agendas — ahora visibilizadas — , se institucionalizó bajo la forma de reuniones especializadas (en la mayoría de los casos) y reuniones de ministros y altas autoridades. Muchas de estas reuniones crearon estructuras técnicas de gestión y de financiamiento permanentes con el objetivo de fortalecer las reuniones y de servir de sustento a los gobiernos a partir de una visión de coordinación regional: institutos, fondos y secretarías técnicas. Además, la concepción de integralidad de las políticas sociales presente en los gobiernos nacionales se diseminó en el escenario regional y se establecieron canales informales de diálogo entre las estructuras institucionales para discutir 
conjuntamente los avances y los obstáculos que enfrentaban. No obstante, la reforma institucional para adecuar este proyecto de Mercosur a las reglas de juego de la integración no fue alcanzada, se reforzaron - como mencionamos - mecanismos políticos de resolución de conflictos en detrimento de soluciones derivadas de un proceso de toma de decisiones regional más equitativo entre la dimensión social y la comercial (Perrotta \& Porcelli, 2016).

El hito que dio inicio al proyecto de Mercosur, que se desarrolló durante la primera década del siglo XXI, fue una reunión cumbre entre los presidentes de Argentina y Brasil en octubre de 2003, que se conoce como el Consenso de Buenos Aires. A partir de aquí se delimitó una hoja de ruta programática con los objetivos a cumplir en diferentes áreas, se recuperó un diagnóstico crítico de la etapa anterior y se regionalizó la coordinación política entre Lula da Silva y Néstor Kirchner. Esto último tuvo su expresión en la aprobación del Plan de Trabajo 20042006 durante la cumbre presidencial de diciembre de ese mismo año. Otro hito relevante en el proceso de construcción de la dimensión social de la integración fue la puesta en marcha, desde junio de 2006, de las Cumbres Sociales del Mercosur, espacios de encuentro y discusión de organizaciones sociales de cada uno de los países para elaborar un pliego de demandas a la cumbre de presidentes. Finalmente, dos innovaciones institucionales que apuntalaron una visión regional para coordinar las diferentes — cada vez mayores y más complejas—iniciativas temáticas fueron, primero, la creación de la Comisión de Representantes Permanentes del Mercosur (CRPM) y, luego, su reemplazo por la figura del Alto Representante del Mercosur. En la órbita de ambas se desarrollaron iniciativas que requerían de un espacio de pensamiento estratégico y de implementación prioritario como el Grupo de Integración Productiva (GIP) y la Unidad de Apoyo a la Participación Social (UPS). Nuevamente, una institucionalidad de gravitación política que no trastocó las reglas de juego imperantes, sino que con la coyuntura favorable, accionó y desarrolló los proyectos regionales.

En las tablas 2 y 3 se presenta la síntesis de la institucionalidad del Mercosur, destacando las áreas de trabajo con injerencia en asuntos sociales, para dar paso a un análisis de las actividades desarrolladas 
por la agenda educativa. Justificamos esta agenda por tratarse de una temática que ha estado presente desde los inicios del Mercosur y se ha configurado y reconfigurado a partir de los proyectos políticos regionales gravitantes de cada momento.

Tabla 2. Instituciones dependientes del смс y del GMC

\begin{tabular}{|l|l|}
\hline \multicolumn{1}{|c|}{ Consejo del Mercado Común (CMC) } & \multicolumn{1}{c|}{ Grupo del Mercado Común (GMC) } \\
\hline - Reuniones de Ministros (16) & $\bullet$ Subgrupos de Trabajo (17) \\
\hline - Grupos (6) & $\bullet$ Reuniones Especializadas (14) \\
\hline - Alto Representante General del & $\bullet$ Grupos Ad Hoc (11) \\
\hline $\begin{array}{l}\text { - Comisión de Coordinación de Ministros } \\
\text { de Asuntos Sociales }\end{array}$ & $\bullet$ Observatorio del Mercado de Trabajo \\
\hline $\begin{array}{l}\text { - Foro de Consulta y Concertación } \\
\text { Política }\end{array}$ & $\begin{array}{l}\text { • Foro Consultivo de Municipios, Estados } \\
\text { Federados, Provincias y Departamentos } \\
\text { del Mercosur }\end{array}$ \\
\hline $\begin{array}{l}\text { - Instituto Mercosur de Formación } \\
\text { Mercosur }\end{array}$ & $\bullet$ Grupos (5) \\
\hline $\begin{array}{l}\text { - Reunión de Altas Autoridades en } \\
\text { Derechos Humanos }\end{array}$ & $\bullet$ Comisión Sociolaboral \\
\hline
\end{tabular}

Fuente: Elaboración propia en base a la información disponible en el sitio www.mercosur.int

Tabla 3. Reuniones de Ministros y Reuniones Especializadas

\begin{tabular}{|l|l|}
\hline \multicolumn{1}{|c|}{ Reuniones de ministros } & \multicolumn{1}{c|}{ Reuniones especializadas } \\
\hline 1. Agricultura & 1. Agricultura Familiar \\
\hline 2. Cultura & $\begin{array}{l}\text { 2. Autoridades Cinematográficas y } \\
\text { Audiovisuales }\end{array}$ \\
\hline $\begin{array}{l}\text { 3. Economía y presidentes de bancos } \\
\text { centrales }\end{array}$ & 3. Ciencia y Tecnología \\
\hline 4. Educación & 4. Comunicación Social \\
\hline 5. Industria & 5. Cooperativas \\
\hline 6. Interior & 6. Defensores públicos oficiales \\
\hline 7. Justicia & $\begin{array}{l}\text { 7. Autoridades de aplicación en materia } \\
\text { de drogas, prevención de su uso indebido } \\
\text { y recuperación de drogodependientes }\end{array}$ \\
\hline 8. Medio ambiente & 8. Estadísticas \\
\hline 9. Minas y energía & 9. Juventud \\
\hline 10. Salud & 10. Ministerios públicos \\
\hline
\end{tabular}




\begin{tabular}{|l|l|}
\hline \multicolumn{1}{|c|}{ Reuniones de ministros } & \multicolumn{1}{c|}{ Reuniones especializadas } \\
\hline 11. Trabajo & $\begin{array}{l}\text { 11. Organismos gubernamentales de } \\
\text { control interno }\end{array}$ \\
\hline $\begin{array}{l}\text { 12. Ministros y altas autoridades de la } \\
\text { mujer }\end{array}$ & 12. Promoción comercial conjunta \\
\cline { 1 - 2 } $\begin{array}{l}\text { 13. Ministros y altas autoridades en } \\
\text { deportes }\end{array}$ & $\begin{array}{l}\text { 13. Reducción de riesgos de desastres } \\
\text { socionaturales, la defensa civil y la } \\
\text { asistencia humanitaria }\end{array}$ \\
\cline { 1 - 2 } 14. Turismo & 14. Turismo \\
\cline { 1 - 2 } $\begin{array}{l}\text { 15. Ministros y altas autoridades de ciencia, } \\
\text { tecnología e innovación }\end{array}$ & \\
\cline { 1 - 1 } $\begin{array}{l}\text { 16. Ministros y autoridades de desarrollo } \\
\text { social }\end{array}$ &
\end{tabular}

Fuente: Elaboración propia en base a la información disponible en el sitio www.mercosur.int

\section{Integración educativa}

La agenda educativa del Mercosur data del inicio del bloque en los años noventa y, si bien no estuvo concebida en el TA, la letra del acuerdo otorgó la "condición de posibilidad" (Perrotta, 2011) para instalar el debate en torno a su incorporación: la libre movilidad de personas del mercado común se facilitaría automáticamente a partir de actividades como el reconocimiento de títulos. La conformación de una comunidad regional precisaba del desarrollo de una conciencia ciudadana favorable a partir de procesos socioeducativos. De esta manera, al "factor habilitante" de la libre movilidad se sumaron elementos contextuales que permitieron la creación del Sector Educativo del Mercosur (SEM) en diciembre de 1991 mediante la decisión del CMC 7/91. Entre estos elementos se destacan, primero, la configuración de un mercado educativo a nivel internacional que tensionó la provisión pública de este servicio y la creciente tendencia hacia la mercantilización de la educación; un aspecto que no fue disonante respecto de la orientación general del Mercosur en su fase inicial. Segundo, la necesidad de crear una identidad regional que legitimara el proceso de integración a partir del fortalecimiento de la ciudadanía. De la convergencia de estos elementos se institucionalizó el SEM y se inició un proceso de acumulación de capacidades y experiencias que acompañó los ciclos políticos nacionales y las etapas por las que transitó el Mercosur. Vale destacar que las pri- 
meras reuniones entre los ministros de educación de los cuatro países fueron apoyadas técnica y financieramente por la OEI que junto con la Organización de Estados Americanos (OEA) financiaron las primeras iniciativas y políticas regionales.

El SEM estuvo organizado hasta el 2011 en tres áreas de trabajo educación básica, técnica y superior-y desde entonces incorporó una cuarta - formación docente-, desarrolladas por un nutrido entramado institucional y planes de trabajo trianuales. La misión y visión de la agenda educativa, plasmada en los planes de trabajo y operacionalizada por medio de actividades, se ha mantenido a lo largo del tiempo, y ha canalizado así diferentes modelos de integración. En este sentido, la hibridez del Mercosur se expresa en esta agenda al observar las finalidades hacia las que se orienta el ejercicio del poder político regional por medio de la puesta en marcha de políticas públicas: desde aquellas que acompañan sin tensionar el modelo de regionalismo abierto hasta las que son más propias del modelo posthegemónico o inclusivo. Esta convivencia de modelos se observa al analizar las iniciativas de las diferentes áreas de trabajo entre sí y especialmente al estudiar el desarrollo de la educación superior —el área más prolífica de las cuatro y la que ha encaminado políticas de más largo aliento e impacto- (ver tabla 4).

Del análisis en profundidad del desarrollo del SEM se desprende que durante los años noventa su condición de agenda periférica, no contrapuesta con los intereses y visiones preponderantes sobre el regionalismo, permitiera encaminar acciones puntuales que contribuyeron a generar el piso sobre el cual se erigió, a partir de los años 2000, una agenda dinámica, pujante y con capacidades de gestión para implementar políticas. En este piso destacan, entre otros elementos, dos cuestiones centrales para comprender la capacidad de puesta en marcha de políticas del SEM: la construcción de confianza y procedimientos regulares de trabajo en el marco regional entre las delegaciones nacionales a partir de un largo proceso de socialización regional de los funcionarios de cada uno de los países, y la relativa estabilidad de los cuadros medios y técnicos que gestionan el día a día de la integración y cooperación educativa. 
Tabla 4. Políticas e iniciativas para la integración educativa (1991-2017)

\begin{tabular}{|c|c|c|}
\hline Etapas del SEM & Políticas e iniciativas encaminadas & Análisis \\
\hline $\begin{array}{l}\text { 1era } \\
(1991-2001) \\
\text { Construcción de } \\
\text { confianza }\end{array}$ & $\begin{array}{l}\text { - Instalación y creación de } \\
\text { institucionalidad mínima en tres } \\
\text { áreas de trabajo (educación básica, } \\
\text { técnica y superior); } \\
\text { - Inicio de los intercambios } \\
\text { entre delegaciones nacionales } \\
\text { que permite un proceso de } \\
\text { construcción de confianza y } \\
\text { respeto mutuo; } \\
\text { - Realización de seminarios } \\
\text { regionales para intercambiar } \\
\text { información (cimiento para la } \\
\text { elaboración de protocolos de } \\
\text { reconocimiento de títulos) y } \\
\text { generar un sistema de indicadores } \\
\text { estadísticos propios. }\end{array}$ & $\begin{array}{l}\text { - Agenda periférica y/o } \\
\text { marginal que no generó } \\
\text { conflictos con el proyecto } \\
\text { regional preponderante de } \\
\text { regionalismo abierto. }\end{array}$ \\
\hline $\begin{array}{l}\text { 2da (2002-2011) } \\
\text { Visibilización }\end{array}$ & $\begin{array}{l}\text { - Creación de una estructura } \\
\text { institucional más compleja, } \\
\text { contemplando la ampliación de } \\
\text { actividades y la comunicación } \\
\text { interna; } \\
\text { - Puesta en marcha de iniciativas } \\
\text { en las áreas de actuación } \\
\text { establecidas en la planificación: } \\
\text { mecanismo experimental de } \\
\text { acreditación, programa de } \\
\text { movilidad estudiantil de carreras } \\
\text { acreditadas, concurso Caminos, } \\
\text { bibliotecas escolares, escuelas de } \\
\text { frontera, parlamento juvenil y } \\
\text { políticas lingüísticas; } \\
\text { - Inicio de un proceso de } \\
\text { socialización regional del } \\
\text { funcionariado nacional y } \\
\text { profesionalización de los cuadros } \\
\text { técnicos de trabajo. }\end{array}$ & $\begin{array}{l}\text { - Contexto regional de crítica } \\
\text { al regionalismo abierto e } \\
\text { insistencia en la promoción } \\
\text { de agendas positivas de } \\
\text { integración: el SEM acompasa el } \\
\text { Consenso de Buenos Aires, el } \\
\text { Plan de Trabajo 2004-2006 y } \\
\text { el proceso de Cumbres } \\
\text { Sociales. } \\
\text { • Visibilización de un conjunto } \\
\text { de déficits (funcional, material, } \\
\text { de legitimidad democrática y } \\
\text { comunicacional) vinculados } \\
\text { a un modelo institucional } \\
\text { anacrónico de regionalismo } \\
\text { abierto. } \\
\text { - Duplicación enunciativa con } \\
\text { la agenda de UNASUR. }\end{array}$ \\
\hline
\end{tabular}




\begin{tabular}{|c|c|c|}
\hline Etapas del SEM & Políticas e iniciativas encaminadas & Análisis \\
\hline $\begin{array}{l}\text { 3era (2011 } \\
\text { - 2015) } \\
\text { Ampliación }\end{array}$ & $\begin{array}{l}\text { - Modificación y complejización } \\
\text { de la estructura institucional } \\
\text { (incorporación de la formación } \\
\text { docente e instancias de apoyo); } \\
\text { - Ampliación de actividades } \\
\text { políticas y programas como } \\
\text { resultado del proceso de } \\
\text { acumulación de capacidades } \\
\text { y recursos, así como de la } \\
\text { maduración de intereses, ideas y } \\
\text { valores compartidos; } \\
\text { - Puesta en marcha de iniciativas } \\
\text { para asegurar la sustentabilidad } \\
\text { financiera: creación del } \\
\text { fondo regional, articulación } \\
\text { con el Focem y búsqueda de } \\
\text { financiamiento externo vía la } \\
\text { cooperación técnica con la Unión } \\
\text { Europea; } \\
\text { - Puesta en marcha del Programa } \\
\text { de Apoyo al Sector Educativo del } \\
\text { Mercosur (PAsEM); } \\
\text { - Creación del Núcleo de Estudios } \\
\text { e Investigaciones en Educación } \\
\text { Superior para promover la } \\
\text { investigación en red; } \\
\text { - Negociación para conformar una } \\
\text { instancia permanente de carácter } \\
\text { técnico de apoyo (en Montevideo); } \\
\text { - Creación del Sistema Integrado } \\
\text { de Movilidad Académica; } \\
\text { - Negociación para elaborar } \\
\text { un programa piloto de } \\
\text { reconocimiento de titulaciones; } \\
\text { Alto Representante General para } \\
\text { la instalación del Estatuto de la } \\
\text { Ciudadanía del Mercosur. }\end{array}$ & $\begin{array}{l}\text { - Autonomización de la } \\
\text { agenda para llevar adelante sus } \\
\text { políticas. } \\
\text { - Persistencia de las } \\
\text { disfuncionalidades de } \\
\text { la arquitectura jurídica- } \\
\text { institucional: caracterización } \\
\text { de agenda periférica y déficits } \\
\text { señalados; } \\
\text { - Ampliación a los Estados en } \\
\text { proceso de Adhesión y nuevos } \\
\text { Asociados. } \\
\text { - Situaciones de } \\
\text { disconformidad con Brasil } \\
\text { por no cumplir con los } \\
\text { compromisos regionales } \\
\text { mientras mantiene una } \\
\text { agenda una doble agenda } \\
\text { de cooperación educativa: } \\
\text { tradicional, con países } \\
\text { centrales; Sur-Sur con } \\
\text { excolonias portuguesas en } \\
\text { África. } \\
\text { - Desafíos para procesar } \\
\text { la suspensión política de } \\
\text { Paraguay, especialmente, como } \\
\text { consecuencia de los logros } \\
\text { y la confianza cimentada en } \\
\text { el proceso de socialización } \\
\text { regional. } \\
\text { - Desafíos para incorporar } \\
\text { la primera ampliación a } \\
\text { un nuevo Estado parte } \\
\text { la agenda de unAsuR. }\end{array}$ \\
\hline $\begin{array}{l}4^{\circ}(2016-. . .) \\
\text { Resiliencia }\end{array}$ & $\begin{array}{l}\text { - Creación del Grupo de Trabajo } \\
\text { en Ciudadanía Regional; } \\
\text { - Profundización de las políticas } \\
\text { regionales en educación superior, } \\
\text { formación docente y lingüísticas: } \\
\text { movilidades y pasantías, } \\
\text { acreditación, reconocimiento de } \\
\text { títulos, en especial. }\end{array}$ & $\begin{array}{l}\text { - Modificación de la } \\
\text { orientación política del } \\
\text { proyecto regional hacia } \\
\text { un regionalismo abierto } \\
\text { recargado: discusiones } \\
\text { en torno a la capacidad } \\
\text { de resiliencia del SEM y su } \\
\text { autonomía para encaminar sus } \\
\text { acciones. }\end{array}$ \\
\hline
\end{tabular}

Fuente: elaboración propia. 
Otro aspecto destacable se refiere a que, pese a ser una agenda periférica del proceso de toma de decisiones del Mercosur, logró que sus iniciativas fueran adoptadas por el GMC y el CMC sin demasiados cuestionamientos ni tensiones. Esto se debió a que en las etapas no contrarió los modelos preponderantes por esta versatilidad interna de diferentes proyectos de integración educativa. A esto se suma el hecho de que ha logrado generar canales de articulación con otras instituciones regionales - pese a la inexistencia de canales formales-y sorteado las dificultades estructurales de ausencia de financiamiento por medio de la búsqueda de fondos externos y, más adelante, conforme lo sucedido en otras áreas del Mercosur, la creación de un fondo educativo (FEM).

Un tercer aspecto del SEM es que la agenda de educación superior, el área de trabajo más gravitante de las cuatro, ha desarrollado políticas regionales con capacidad de difusión a los marcos normativos nacionales, que ha derivado en algunos países en procesos de cambio de política (Perrotta, 2016). De esta manera, la agenda educativa del Mercosur muestra cómo el regionalismo conforma marcos regulatorios que afectan la gobernanza nacional a través del impacto en la política doméstica (Perrotta, 2016). En este proceso, Argentina - por motivos que se detallan a continuación - ha sido un actor difusor de las políticas por medio de actividades de cooperación técnica y como un miembro activo en redes epistémicas regionales y globales.

$\mathrm{Al}$ analizar el proceso anterior se destaca un cuarto elemento saliente del manejo de la agenda de integración educativa: cómo las asimetrías estructurales y regulatorias en el sector de la educación, junto con las diferencias de lo que denominamos tradiciones educativas y culturas académicas, inciden en el proceso de tematización, formulación, adopción, implementación y evaluación de políticas públicas regionales. En efecto, del estudio de las acciones del Mercosur en sus cuatro agendas, pero especialmente en la de educación superior (Perrotta, 2013; 2016), se puede afirmar que la peculiaridad de las políticas educativas regionales se entiende más atendiendo a los aspectos regulatorios de los países sedimentados en trayectorias históricas e identitarias vinculadas a las tradiciones educativas y culturas académicas, 
en detrimento del tamaño de cada uno de los sistemas. En efecto, la concepción de la educación como bien público y derecho humano visa-vis la noción de la educación como mercancía y la economía basada en el conocimiento dividen aguas respecto de cómo desarrollar la agenda de integración educativa: sus características y los alcances de las políticas. Del estudio en profundidad de esta agenda se observa un liderazgo argentino basado en una fuerte tradición de educación pública y una cultura académica según el paradigma del derecho a la educación y autonomía universitaria que moldeó mayoritariamente las acciones del SEM y especialmente del área de educación superior. En este proceso, Brasil ha seguido la orientación de acompañar la posición argentina, priorizando la cooperación birregional para luego regionalizarla en el espacio del Mercosur. Finalmente, esta relación entre asimetrías regulatorias y estructurales junto con la dimensión vinculada a la cultura e identidad permiten explicar también cómo el SEM ha encaminado políticas regionales que se diferencian de las corrientes centrales de regionalización educativa, promoviendo instrumentos de política que critican los modelos actuales y los readecuan a las peculiaridades mercosurianas.

Un quinto factor es, en el plano institucional, la ausencia de un espacio de coordinación técnica regional que contribuya a organizar el trabajo por delegaciones nacionales más allá de quién tiene la titularidad de las presidencias pro tempore y la ausencia de participación de actores no gubernamentales. Estos dos elementos, que caracterizan el trabajo de las reuniones especializadas del Mercosur creadas en el escenario posterior al 2000 no han logrado tener resonancia en el SEM, un poco por la misma construcción de la institucionalidad y la acumulación de capacidades de los actores gubernamentales, que impermeabilizaron el trabajo con actores interesados como universidades, sindicatos docentes y organismos no gubernamentales vinculados a la educación.

En la actualidad, el cambio de ciclo político —a diferencia de otras agendas sociales - muestra un escenario de reacomodamiento. La versatilidad de la agenda, propia de su hibridez, lleva a un reequilibrio de las iniciativas. No obstante, durante el 2016 y hasta el primer semestre del 2017, cierta inercia institucional — que se puede explicar 
a partir de la permanencia de un conjunto de actores gubernamentales interesados y que comparten valores en torno a la integración educativa - permanece y de hecho lograron aprobarse proyectos que venían gestándose en el ciclo anterior. Tres iniciativas destacan: por un lado, la puesta en marcha de la primera prueba piloto de reconocimiento de títulos (un tema pendiente del Mercosur educativo desde sus inicios y que fue el que llevó a la conformación del SEM y de la primera política de acreditación regional); por otro lado, la conformación de un sistema integral de movilidad académica regional (SIMercosur) para mejorar estas acciones y centralizarlas en una secretaría técnica con sede en Montevideo, que se estimula a partir del trabajo con el Instituto Social del Mercosur (ISM) para la puesta en marcha del Estatuto de Ciudadanía en el año 2020. Finalmente, la creación del GT de ciudadanía regional. En este sentido, acciones más "propias" del ciclo anterior están logrando ser articuladas en el nuevo escenario un poco por inercia y capacidad de trabajo de los organismos regionales, otro poco porque un legado del regionalismo posthegemónico ha sido la conformación de pisos mínimos en términos de derechos regionales.

El análisis del SEM permite identificar rasgos de diferentes formas de construcción de región y regionalismo en sus cuatro etapas. Efectivamente, su creación como agenda periférica forma parte de la hibridez inicial del Mercosur: una institucionalizada en un TA ecléctico que plantea objetivos programáticos vinculados al regionalismo abierto y metas de largo aliento enraizadas en el modelo de regionalismo autonómico de los años sesenta y ochenta. Esta flexibilidad del TA para acoger proyectos divergentes de construcción de región fueron la condición de posibilidad para la instalación de una agenda educativa regional que, en sus documentos fundacionales (Protocolo de Intenciones, Planes Operativos) combinó elementos de un regionalismo educativo orientado a las tendencias mundiales de mercantilización con aspectos que salvaguardaron las peculiaridades cimentadas en la larga tradición de educación pública de dos de los Estados parte (Argentina y Uruguay). Esta diferenciación entre la perspectiva de derechos y experiencias de privatización fueron plasmadas en los tipos de regionalismo que se sucedieron en el Mercosur y a la vez es un 
elemento central en la discusión en torno a las asimetrías nacionales -regulatorias, estructurales y de culturas o tradiciones educativas-.

El desarrollo prolífico del SEM del momento posthegemónico permite dar cuenta de la hibridez a que aludimos: la agenda de integración educativa es visibilizada en el marco del lanzamiento de la institucionalidad social del Mercosur, acompasada por las iniciativas de participación de movimientos sociales y construcción de la ciudadanía regional, que permitió la puesta en marcha de políticas e iniciativas, que al mismo tiempo imposibilitó la reforma del modelo político-decisional e hizo que la institucionalidad social mantuviera su condición periférica — tal cual el esquema "típico" del regionalismo abierto- Así, en un contexto postliberal de priorización de políticas inclusivas y redistributivas en los escenarios nacionales, el SEM no contó con obstáculos considerables para llevar adelante sus diferentes actividades. En el actual escenario de giro político hacia la derecha, la hibridez se explicita en la capacidad de resiliencia de la agenda educativa cimentada en la acumulación de capacidades institucionales y una burocracia técnica profesionalizada y socializada en el espacio regional.

\section{Conclusiones}

Luego de tantas décadas de análisis del regionalismo, de la integración regional, del regionalismo comparado, de la cooperación y concertación regional, entre diferentes categorías para asir la forma en que un conjunto de países deciden poner en común aspectos de su política doméstica con miras a alcanzar metas específicas, es posible afirmar — sin miedo a equivocarnos- que cada proceso de integración o bloque regional es único, depende de su historia previa, geografía, condiciones socioeconómicas, herencias culturales e identitarias. En línea con este pensamiento, este trabajo echó luz sobre algunos aspectos del Mercosur que lo hacen, no solo un bloque regional único, sino también un proceso híbrido y complejo.

Estas características permiten entender al Mercosur como un acuerdo regional sobreviviente —o "resiliente" (Dabène, 2012; Puntigliano 
\& Briceño-Ruiz, 2013; Sanahuja, 2016)—, que ha atravesado en su cuarto de siglo ciclos políticos diferentes y divergentes y oleadas de integración contrapuestas. Tal como hemos demostrado a lo largo del trabajo, varias agendas del Mercosur no siguen los patrones preestablecidos por los modelos prescriptivos de regionalismo (cualquiera que sea). Al contrario, estos modelos inciden en el proceso político de construcción de región, permeando las políticas regionales que se encaminan. Incluso, en un mismo momento o etapa, es posible observar la coexistencia de dos modelos: el bloque refleja ese arrastre y superposición de agendas a través de las oleadas, algunas más orientadas a la liberalización comercial, otras en línea con rasgos salientes de la tercera oleada e incluso reminiscencias de la primera oleada que en términos de discusiones como las de política de integración productiva siguen apelando a este momento histórico y conjunto de ideas.

En tanto su complejidad se incrementa por la combinación de diferentes modalidades de integración regional presentes en forma de capas que se van añadiendo, las variadas formas de construcción de región conviven de manera errática a lo largo del tiempo y en relación a los elementos del contexto político, económico y social general; a veces en tensión, otras en armonía circunstancial resultante del pragmatismo de la diplomacia presidencial.

Asimismo, en toda su historia persisten elementos estructurales que configuran un elemento nodal para comprender la supervivencia del bloque. Como se pudo observar, este núcleo estructurante es la alianza estratégica entre Argentina y Brasil, potenciada por una esencia de intereses regionales que sostienen un comercio intrarregional modesto pero constante en el tiempo, además de considerables niveles de protección industrial hacia la extrazona. Esto no implica aseverar que se relegan los demás países del Mercosur — los demás Estados partes y asociados - a una posición periférica o menospreciable en el proceso político regional, de hecho en varias agendas han sido actores centrales para promover iniciativas en pos de la resolución de asimetrías y la atención a temas puntuales. 
La hibridez del Mercosur — que lo dota de flexibilidad para adecuarse a ciclos políticos diversos - junto con los elementos estructurales observados, y especialmente el consenso argentino-brasileño como eje de funcionamiento, permiten esbozar algunas reflexiones sobre el contexto actual. Hoy por hoy, el bloque atraviesa nuevamente un momento de reconfiguración al calor del significativo cambio de contexto político que se sucede al mismo momento de una importante crisis económica y social en varios de los países que lo conforman. Aún más, este momento coincide con dos desafíos que se vienen dando desde el 2012: procesar su primera ampliación (Venezuela) en paralelo a la suspensión y posterior reincorporación de un Estado parte (Paraguay).

Todo esto ha de procesarse en un marco donde los demás acuerdos regionales sudamericanos están en un proceso de reconfiguración, especialmente: la gravitación mediática que está atrayendo la Alianza del Pacífico — en tanto espacio de profundización del nuevo regionalismo y que se emparenta en algunos aspectos con el llamado regionalismo del siglo XXI (Baldwin, 2011) — y el estado vegetativo de la UNASUR — que había sido EL modelo exitoso de regionalismo posthegemónico-.

En ese contexto, algunas agendas vuelven a ganar impulso como las negociaciones con países desarrollados; otras probablemente perderán espacio como la de agricultura familiar o el tema de asimetrías. Otras, llamativamente y pese al "cambio", se están profundizando como educación, donde resulta significativo profundizar medidas tendientes al reconocimiento de estudios, la movilidad académica - y eventualmente, la movilidad de trabajadores - y la puesta en marcha de actividades que busquen la conformación de una ciudadanía regional.

En este proceso, el Mercosur también posee capacidad de respuesta tanto por la conformación de un conjunto de funcionarios socializados regionalmente que - pese a los cambios en las altas estructuras de gobierno- pueden seguir pujando por políticas regionales que van incorporando las modificaciones de los ciclos políticos, adaptándolas tanto por la conformación de instituciones técnicas regionales, 
como por el Instituto Social del Mercosur o el reciente Parlamento del Mercosur que van sumando al acervo regional. No obstante, sigue siendo imperioso un proceso de pensamiento estratégico para superar el diagnóstico de "bloque sobreviviente" en pos de hacerlo protagonista de políticas regionales transformadoras.

\section{Referencias}

Aponte García, M. (2015). El nuevo regionalismo estratégico. Los primeros diez. años del ALBA-TCP. Buenos Aires: CLACSO.

Baldwin, R. (2011). "21st century regionalism: Filling the gap between 21st century trade and 20th century trade rules". En: World Trade Organization (WTO), Economic Research and Statistics Division. ERSD-2011-08. Ginebra.

BID-INTAL. (2012). Informe Mercosur 17 - segundo semestre 2011, primer semestre 2012. Recuperado de https://publications.iadb.org/bitstream/ handle/11319/5617/Informe_MERCOSUR_N_17.pdf?sequence $=2$ BID-INTAL. (2015). Informe Mercosur 20, Segundo semestre 2014-primer semestre 2015, Instituto para la Integración de América Latina y el Caribe (INTAL). Nota técnica del BID, IDB-TN-876.

BID-INTAL. (2017). Los futuros del Mercosur. Nuevos rumbos de la integración regional, Instituto para la Integración de América Latina y el Caribe (INTAL). Nota técnica del BID, 1263.

Botto, M. (2015). La integración productiva como un símbolo de un cambio de época: del neoliberalismo a una visión desarrollista. En M. Botto (Ed.), La integración regional en América: Quo vadis? El Mercosur desde una perspectiva sectorial y comparada (pp. 45-110). Buenos Aires: Eudeba.

Botto, M., \& Quiliconi, C. (2007). La influencia de la academia en la política arancelaria del Mercosur. En M. Botto (Ed.), Sabery política en América Latina. El uso del conocimiento en las negociaciones comerciales internacionales (pp. 209-245). Buenos Aires: Prometeo.

Bouzas, R. (2003). "Mecanismos para compensar los efectos de las asimetrías de la integración regional y la globalización. Lecciones para America Latina". Documento preparado para el seminario "Global y Local: El Desafío del desarrollo regional en América Latina y el Caribe”, BID, 22 de marzo, Milán, Italia. Recuperado de: http://www. 
sela.org/media/267971/t023600001667-0-mecanismos_para_compensar_los_efectos_de_las_asimetr $\% \mathrm{C} 3 \% \mathrm{AD}$ as.pdf

Briceño Ruiz, J. (2006). Modelos de desarrollo y estrategias de integración en América Latina: una revisión crítica. Cuadernos sobre relaciones internacionales, regionalismo y desarrollo, 1(1), 63-87.

Briceño Ruiz, J. (2011). Del regionalismo estratégico al regionalismo social y productivo. Las transformaciones del modelo de integración en el Mercosur. En J. Briceño Ruiz (Ed.), El Mercosury las complejidades de la integración regional (121-162). Buenos Aires: Teseo.

Caetano, G., Vazquez, M., \& Ventura, D. (2009). Reforma institucional del Mercosur: análisis de un reto. En G. Caetano (Ed.), La reforma institucional del Mercosur. Del diagnóstico a las propuestas (pp. 21-77). Montevideo: Trilce.

Calfat, G., \& Flores Júnior, R. (2001). Questões de geografia econômica para o Mercosul. En D. Chudnovsy \& J. M. Fanelli (Eds.), El desafío de integrarse para crecer. Balances y perspectivas del Mercosur en su primera década. Buenos Aires: Red Mercosur-Siglo xxi Editores.

Celli, U., Salles, M. Tussie, D., \& Peixoto, J. (2011). Mercosur in south-south agreements: In the middle of two models of regionalism. Recuperado de http:// vi.unctad.org/digital-library/ ?act=search\&doc=574-mercosur-in

Dabène, O. (2009). The politics of regional integration in Latin America: theoretical and comparative explorations: Palgrave: Macmillan.

Dabène, O. (mayo 2012). Explaining Latin America's fourth wave of regionalism. Regional integration of a third kind. Ponencia presentada en el Congress of the Latin American Studies Association, San Francisco, CA, Estados Unidos de América.

Fossati, V., \& Levit, L. (2010). El sistema global de preferencias comerciales entre países en desarrollo: Una oportunidad para el comercio exterior argentino. Revista del CEI, (17).

Gómez Mera, L. (2005). Explaining Mercosur's survival: Strategic sources of Argentine-Brazilian Convergence, Journal of Latin American Studies, 37, 109-150.

Gómez Mera, L. (2008). How 'new' is the 'New Regionalism' in the Americas? The case of Mercosur. Journal of International Relations and Development, 11, 279- 308.

Inchauspe, E., \& Perrotta, D. (2008). El Mercado Común del Sur: ¿más que un acuerdo de integración regional comercial? Trabajo presentado en las Jorna- 
das de Jóvenes Investigadores de la Asociación de Universidades del Grupo Montevideo.

Inchauspe, E. (2009). Integración productiva en el Mercosur: continuidades y rupturas en esta nueva agenda de cooperación regional. Trabajo presentado en el IX Congreso Nacional de Ciencia Política de la Sociedad Argentina de Análisis Político.

Motta Veiga, P., \& Ríos, S. (2007). O regionalismo pós-liberal, na América do Sul: origens, iniciativas e dilemas. Santiago de Chile: CEPAL.

Ocampo, J. A. (2011). Seis décadas de debates económicos latinoamericanos. Recuperado de http://policydialogue.org/files/events/SEGIB-PNUD_ Ocampo-final.pdf

Paikin, D., \& Dulcich, F. (2017). El sexto socio del Mercosur: un estudio sobre la penetración importadora china y su impacto en el comercio intrarregional. Revista Perspectivas de Politicas Públicas, 6(12).

Peixoto, J. (2010). Flexibilities for developing countries in the Doha Round as À La Carte special and differential treatment: Retracing the Uruguay steps. Brazilian Journal of Latin American Studies, 9(16), 164-191. Recuperado de http://www.usp.br/prolam/downloads/2010_1_9.pdf

Perrotta, D., Fulquet, G., \& Inchauspe, E. (2011). Lucesy sombras de la internacionalización de las empresas brasileñas en Sudamérica: ¿integración o interacción? Buenos Aires: Documentos Nueva Sociedad.

Perrotta, D., \& Vazquez, M. (2010). El Mercosur de las políticas públicas regionales. Las agendas en desarrollo social y educación. Montevideo: CEFIR - In Went. Perrotta, D. (2013). El regionalismo de la educación superior en el proceso de integración regional del Mercosur: políticas de coordinación, complementación, convergencia y armonización en las iniciativas de acreditación de la calidad de carreras de grado (1998-2012). (Tesis doctoral, Facultad Latinoamericana de Ciencias Sociales, Buenos Aires, Argentina).

Perrotta, D. (2016). Mercosur, regulatory regionalism and contesting projects of higher education governance. En S. Robertson, K. Olds, R. Dale \& Q. Anh Dang (Eds.), Global Regionalisms and Higher Education. London: Edward Elgar.

Perrotta, D., \& Porcelli, E. (2016). Mercosur 25 años: desafíos en su nueva etapa. Márgenes. Revista de Economía Política, 2(2), 53-72.

Porta, F. (2006). Cómo reinsertar el Mercosur en una agenda de desarrollo. Problemas y políticas. Cuadernos del CENDES, 23(63), 26. 
Puntigliano, A. R., \& Briceño-Ruiz, J. (2013). Resilience of regionalism in Latin America and the Caribbean: Development and autonomy. Nueva York: Macmillan.

Quiliconi, C. (2013). Modelos competitivos de integración en el Hemisferio Occidental: ¿liderazgo competitivo o negación mutua? Revista CIDOB d'afers internacionals, (102-103), 147-168.

Riggirozzi, P., \& Tussie, D. (Eds.) (2012). The rise of post-hegemonic regionalism. The case of Latin America "Chapter 1". New York: Springer.

Sader, E. (2009). El nuevo topo. Los caminos de la izquierda Latinoamericana. Buenos Aires: Siglo XxI editores-Clacso.

Sanahuja, J. A. (2012) Regionalismo post-liberal y multilateralismo en Sudamérica: el caso de UNASUR. Anuario de la Integración Regional en América Latina y el Gran Caribe Revista CRIES 30 Aniversario, 115-158.

Sanahuja, J. A. (2016). Regionalismo e integración en América Latina: de la fractura Atlántico-Pacífico a los retos de una globalización en crisis. Pensamiento propio, 21(44), 29-76.

Sánchez Bajo, C. (1999). Mercosur's open regionalism and regulation: Focusing on the petrochemical and steel sectors. Iberoamericana - Nordic Journal of Latin America and Caribbean Studies, 29(1-2).

SELA. (2015). Informe de evaluación del comercio intrarregional en América Latina y el Caribe, 1980-2013. Recuperado de http://www.sela.org/media/268486/informe_evaluacion_comercio_intrarregional_alc_19802013_.pdf

Teubal, M. (1968). El fracaso de la integración económica latinoamericana. Desarrollo Económico, 8(29), 61-93.

Trucco, P. (2017). "Políticas de articulación productiva”, en Los futuros del Mercosur. Nuevos rumbos de la integración regional, Instituto para la Integración de América Latina y el Caribe (INTAL). Nota técnica del BID, 1263, 112-123.

Tussie, D., Botto, M., \& Delich, V. (2004). El Mercosur en el nuevo escenario político regional. Nueva Sociedad, (186), 114-127.

Tussie, D., \& Heidrich, P. (febrero 2008). Políticas económicas y comerciales de la nueva izquierda: ¿populistas o conservadoras? En Documento de Trabajo Área Relaciones Internacionales FLACSO/Argentina.

Vallado, A. (2007). The new Tordesillas line: The present great Latin America East-West divide. Quaderni LAI (4). 
Vázquez, M. (2011). El Mercosur social. Cambio político y nueva identidad para el proceso de integración regional en América del Sur. En G. Caetano (Ed.), Mercosur 20 años (pp. 165-187). Montevideo: Centro de Formación para la Integración Regional - CEFIR.

Vilas, C. (2011). Después del neoliberalismo: estado y procesos políticos en América Latina. Buenos Aires: Ediciones de la UNLa. 